No. 1

February 2016

\title{
UNIVERSITY-INDUSTRY PARTNERSHIPS AND OPEN INNOVATION
}

\section{KEY DEVELOPMENTS AND EXPERIENCES FROM THE UNIVERSITY OF CAMBRIDGE}

doi.org/ 10.17863/ CAM. 13932

Tim Minshall (CTM, University of Cambridge) *

Letizia Mortara (CTM, University of Cambridge)

Tomas Ulrichsen (CSTI, University of Cambridge)

* Please contact the corresponding author for feedback: thwm100@eng.cam.ac.uk

A prior version of the paper was presented at the 2nd Annual World Open Innovation Conference, Santa Clara, 19-20th November 2015 
University-industry partnerships and open innovation implementation: Key developments and experiences from the University of Cambridge.

Tim Minshall, Letizia Mortara, Tomas Ulrichsen

University of Cambridge Institute for Manufacturing, 17 Charles Babbage Road, Cambridge CB3 OFS, UK.

tim.minshall@eng.cam.ac.uk,Im367@cam.ac.uk,tc267@cam.ac.uk

\begin{abstract}
This paper analyses the relationships of one UK-based research-intensive university with a number of leading multinational firms at different points along parallel processes of organisational development. From this, we have identified approaches used and problems encountered at different stages, and drawn lessons that can support corporate and university decision makers in establishing and managing successful partnerships.
\end{abstract}




\section{Introduction}

This paper explores the links between the emerging strategic importance and institutionalization of innovation and industry engagement activities in universities, and the diffusion of open innovation (OI) practices in multinational corporations. We select the University of Cambridge as an example of a large, globally leading research-intensive university that has witnessed major transformations in its approach to innovation and engagement with a broad range of industrial partners. As a university made up of 31 self-governing colleges, over 150 relatively autonomous schools, departments and institutions, and limited centralised control, Cambridge is unique in many ways. As such, it provides an outlier example, where it might be expected that the institutionalisation of industrial engagement and a higher rate of participation in industrial innovation would be less easy to implement than in more coordinated universities. In addition, Cambridge has a long history of working with large, researchintensive firms that have been on their own Ol journey. The university thus provides a valuable case to examine the issues in these transformation processes and how these journeys have co-evolved.

We first review the evolving innovation-related policy context for universities in the UK, then focus on the impact of such policies on activities at University of Cambridge over a 20-year period. We then examine the emergence of the open innovation (OI) paradigm and the impact it has had on the innovation strategies of firms in wide range of industries. We draw parallels between the stages of Lewin's process of organisational change that can be observed during firms' implementation of OI with the phases of implementation of innovation and industry engagement activities within a university context. Next, we draw upon six case studies of firms that have engaged with the University of Cambridge at different stages of the firms' implementation of Ol, and at different stages of the University's implementation of its innovation support programmes. From this, generic lessons are drawn that can provide guidance to industry and university managers tasked with establishing and managing university-industry partnerships. 


\section{Evolving UK context for innovation and university-industry engagement}

\subsection{Evolution of UK government policies}

The past 20 years have seen universities become increasingly important components of science and innovation policies in the United Kingdom (UK) and elsewhere, with growing pressures from government and industry for them to become increasingly strategic actors in processes of innovation and economic developmentii. Indeed, universities have been evolving to become more deeply and strongly linked into the innovation system, more directly engaged in processes of innovation ${ }^{\text {iii. }}$

Given that UK universities are largely publicly funded - albeit autonomous - institutions, their evolution cannot be separated from the shifting public policy landscape relating to science and innovation. A range of government-related factors is identified in the literature, not least the longterm shift in advanced economies towards knowledge-based production resulting in governments placing much greater emphases on science and innovation and the potential for universities to play a more active and strategic role. In the UK there is also (i) a belief among policymakers that rebalancing of economies away from services would greatly benefit from the strengthening of the commercialisation of university research; (ii) significant and intensifying pressures on public spending leading to demands for greater accountability and demonstration of impacts from these investments; and (iii) the collapse of government funding in the physical sciences since the early 1990s leading to growing pressures on universities to pursue alternative funding sources.

Within this broad context, there have been significant developments in the UK policy landscape supporting university-industry collaborations over the past 20 years that have shaped institution-level approaches and activities. The seeds of change in the UK were sown back in 1994 with the publication of a government strategy entitled, "Realising Our Potential: A Strategy for Science, Engineering and Technology"iv . The document called for the UK to develop a much stronger and systemic partnership between the research base and industry and re-emphasise technology transfer policies to encourage the interchange of ideas, skills, know-how and knowledge between these parts of the innovation system. The strategy document set the scene for a 20 -year period of transformation within UK 
universities resulting in a much more systematic and strategic approach emerging in support of technology diffusion and innovation within industry.

Analysis of the UK experience suggests three distinct policy development phases: experimentation between 1999 and 2004; consolidation between 2004 and 2008; and institutionalisation between 2008 and 2015.

\section{Policy Experimentation, 1999-2004}

The introduction of dedicated resources for universities to strengthen their 'knowledge exchange' (KE) ${ }^{v}$ linkages with industry to support technology diffusion and innovation began in earnest in 1999. This followed growing evidence of significant barriers hampering the formation of productive partnerships between universities and firms ${ }^{\mathrm{vi}}$. This included the lack of capability and capacity to engage with industry, a culture within the academy that was averse to such activity ${ }^{\text {vii }}$, and the lack of an institutional framework for industrial collaboration ${ }^{\text {viii. }}$

In response, the UK government introduced a range of schemes available to universities - at the institutional level - to address these challenges ${ }^{i x}$. These were distinct from universities' core funding for research and teaching. They covered different broad areas of activity including building capability and capacity to engage; enterprise and entrepreneurship education; and seed funding for early stage ventures arising from research. The funds were allocated based on largely fixed-term projects (covering the period 1999-2003), and secured through competitions. Crucially, the range of funding schemes aimed to provide the incentives and underpinning resources for universities to explore and experiment in different approaches to industrial engagement and commercialisation in support of innovation and knowledge diffusion ${ }^{\mathrm{x}}$.

\section{Consolidation, 2004-2008}

This initial period of experimentation was followed by a period of consolidation, with the range of schemes consolidated into a single fund for KE: the 'Higher Education Innovation Fund' (HEIF). It was 
introduced in 2001/02 incorporating the existing 'Higher Education Reach-Out to Business and the Community' (HEROBC) funding focusing on building capacity and capability within universities to engage with industry in areas that would lead to innovation and wealth creation. It was deliberately broad in scope recognising the many ways through which universities could contribute to innovation. Plans were also announced by the government to consolidate HEIF as a permanent stream of funding - alongside to research and teaching - to support knowledge exchange, and significantly increase its scale.

At this time a major review of university-business collaboration in the UK - the Lambert Review ${ }^{\mathrm{xi}}$ - was concluded, bringing together significant learning about how policies in this space could be strengthened. It recognised the importance of these funds in enabling universities to strengthen their engagement with industry. However, it called for significant increases in the scale of funding while maintaining the broad scope of the funding in enabling universities to support a wide range of interaction mechanisms in different sectors of the economy.

The Lambert Review also identified particular challenges faced by universities in developing the necessary capabilities and capacity for interacting with industry. The short-term, time-limited and project-based funding made it very difficult for universities to plan for the longer term including their ability to hire high quality staff, who were often turned away by short, fixed-term contracts. The report called on the government to develop mechanisms to provide greater stability and longevity for the funding. To achieve this, the government reformed HEIF, switching it in 2006/07 away from a competition-driven, project-focused funding approach to a part-formula, part-competition based allocation method. This aimed at providing universities with a much larger degree of flexibility and stability enabling them to build longer term capacity, including the ability to professionalise their KE support staff by creating dedicated career pathways in this areaxii. In return for this increased flexibility and stability, universities had to produce institutional strategies and forward looking business plans that would guide the internal allocations of funding. 
The period of consolidation has been followed by one of growing institutionalisation of KE funding, beginning around 2008. This sees HEIF move to a fully formulaic approach (i.e. funding is allocated to all universities and the amount of money allocated to individual institutions is based on previous performance) backed up by institutional strategies for investing the funds. It is also increased in scale to $f 150$ million per annum, despite the increasingly challenging fiscal climate brought on by the onset of the 2008 recession. This reflects the continuing recognition by the government in the need to focus not just on the production of knowledge, but also its diffusion through close partnerships between academia and industry as well as the recognition of the strategic roles that universities could play in addressing major national socio-economic, industrial, technological challenges. This period also sees the government and its research funding agencies implement major changes to the system-wide incentives facing academics and universities with considerations of knowledge diffusion and 'impact' explicitly included in research grant allocations. In 2012, the government introduced a new funding scheme for large-scale, longer-term research and innovation infrastructure with university-industry partnering at its core $\mathrm{e}^{\mathrm{xii}}$. This scheme requires 2:1 leveraged funding from industry. The initial round was heavily oversubscribed, leading to joint investments of over $f 1$ billion in such infrastructure ${ }^{\text {xiv }}$.

The most recent review of university-business research collaborations ${ }^{\mathrm{xv}}$ recognises the importance of this type of funding for universities and calls on the government to make a long-term commitment to ensure it remains a core part of the funding landscape for UK universities. The position of universities within the national innovation landscape is now commonly and explicitly given in terms of Technology Readiness Levels, and the complementary roles that universities are expected to play in relation to other publicly funded innovation-targeted agencies, most notably InnovateUK $K^{\mathrm{xvi}}$.

\subsection{Development of Innovation and Industrial Engagement at the University of Cambridge}

The approach taken by the University of Cambridge in developing its approach to innovation and industrial engagement has been guided by the changing policy context described above, but has also 
been highly influenced by its own history, culture, and position within its regional economy. The University's approach can be seen to have passed through four broad phases: pre-1999 (diffuse, liberal approach); 1996-2004 (experimentation); 2004-2010 (consolidation); and 2010-present (institutionalization) $^{\text {xvii }}$.

Pre-1999: a diffuse and liberal approach to knowledge transfer

Examples of innovation and industrial engagement can be seen throughout the history of the University of Cambridge. The Cambridge University Press was established in 1534, there are examples of new scientific instrumentation companies emerging from the University in the 1800 s, and a major investment in 1945 by the energy company Shell led to the creation of the Department of Chemical Engineering.

However, industrial collaboration and commercialisation was a regarded largely spillover effect of the core academic research activities with the University adopting a diffuse and passive, liberal approach $^{\text {xviii }}$. Some initiatives were launched, but these largely emerged from the academic community, not from any central policy. For example, in 1970 the Department of Engineering set up the Wolfson Industrial Liaison Office (WILO) and tasked it with dealing with, and facilitating, the research commercialisation activities of the department. Following the publication of the Report of the Mott Committee ${ }^{\mathrm{xix}}$ that highlighted the potential role Cambridge could play in regional innovation, Trinity College - one of the wealthiest Cambridge colleges - established the Cambridge Science Park. The establishment of this park is credited as one of the key catalysts for the emergence of the city as a major high-technology cluster. The University also had very liberal intellectual property rights policies (IPR) with individual academics having significant freedom to negotiate IPR with industrial sponsors and in how they approached research commercialisation. In 1988 the University set up the Cambridge Programme for Industry (CPI) as part of the Board of Continuing Education to provide professional development and executive education for industry. A spillover benefit from this activity was the seeding of some deep, long-lasting relationships between the University and companies ${ }^{\mathrm{xx}}$. 


\section{Experimentation (1996-2004)}

In 1996, the University of Cambridge appointed a new Vice Chancellor, Alec Broers, who would fundamentally alter the approach of the university towards industrial engagement and innovation. Alec Broers had a successful mixed academic-industrial background, having been a researcher at the IBM Corporation, Professor of Electrical Engineering at Cambridge, the Head of the Cambridge Engineering Department and non-executive director of Lucas Industries (at the time a large UK manufacturer of components for the automotive and aerospace industries). In 1998 he commissioned a review into how the University engages with industrial and commercial bodies. This review identified the need for a new approach that could provide a more systematic, efficient and adequately resourced framework for innovation and industrial engagement.

The completion of this review coincided with the UK government's launch of the range of competitive funding programmes described in the previous section that made available dedicated institution-level funds to support innovation and industrial engagement. The strategic imperative provided by the new Vice Chancellor coupled with the availability of dedicated, institution-level resources heralded a period of significant experimentation in its structures and processes to engage with industry to support innovation and the commercialisation of technologies and driven by the University rather than individual academics or departments. Key experiments emerging over the next few years included:

- The Cambridge Entrepreneurship Centre (CEC) providing education, training and support for the formation and growth of new ventures based on University research. It also established and ran an early stage business incubator within the University.

- A centrally located Corporate Liaison Office (CLO) that aimed to identify and nurture relationships with industry, both with large companies and the University's interface with the city's high technology cluster. The office was to act as an initial access point for companies wishing to engage with the University, particularly for those who had not done so previously. Within this 
office, the Corporate Liaison Programme (CLP) was established, modelled loosely on the Industrial Liaison Programme (ILP) at the Massachusetts Institute of Technology (MIT). The CLP was given resources to develop tailored approaches for companies engage with to the University, and explore opportunities for developing longer-term relationships. Initial members included major UK, European and US multinational firms ${ }^{\mathrm{xxi}}$.

- The University Challenge Fund (UCF), a seed-stage equity investment fund supporting early stage commercial exploitation of inventions arising from the University's research.

- A centrally located Research Services Division (RSD) tasked with supporting the research of individual academics and research groups. This incorporated Wolfson Industrial Liaison Office (WILO), which had evolved into the University's Technology Transfer Office (TTO).

- Creation of University-wide thematic research strategies in multidisciplinary areas of importance to the UK economy aimed at targeting research more strongly influenced by industrial and societal need.

During this period of experimentation, the University also began to revise its liberal IPR policies ${ }^{\mathrm{xxi}}$. In 2003, the University established a working group on IPR to explore future changes. This began to bring the University in line with the majority of other UK universities. In addition, it began exploring the potential to create a nexus of innovation activity at 'West Cambridge', co-locating the University's entrepreneurial and commercially-oriented services in a relatively new campus being development to the west of the city.

At the same time, the UK's New Labour government funded a major US-UK partnership between the University of Cambridge and MIT (the Cambridge-MIT Institute ${ }^{\text {xiii }}$ ) that aimed to explore and share practice on how academics, industrialists and educators might work together to stimulate competitiveness, productivity and entrepreneurship. 


\section{Consolidation, 2004-2008}

The initial period of experimentation by the University was followed by a period of learning and consolidation within the evolving national public funding landscape and growing government prioritisation of knowledge exchange as an important part of a university's portfolio of activities. The switch in public funding for innovation and industrial engagement from competitive, time-limited projects to formula-driven allocation during this period provided greater flexibility and stability for Cambridge to invest longer term in its support infrastructure. In addition, the latter half of the period saw the growing importance of 'potential impact' in research funding allocation decisions.

Many of the core structures created in the previous period persisted albeit with some reform, restructuring and consolidation. The creation of Cambridge Enterprise (CE) in 2004 (which was incorporated into a limited company wholly owned by the University in 2006) brought together the Technology Transfer Office (TTO), the University Challenge Fund (UCF) and the practice-related elements of the Cambridge Entrepreneurship Centre (CEC). The focus of this consolidated structure was on IP protection, technology licensing negotiations and supporting new venture creation. It also continued its support for consultancy activity and providing technology showcases and industryacademia networking. The education and training elements of CEC were separated to create the Centre for Entrepreneurial Learning (now part of the Judge Business School). The Corporate Liaison Office and its Corporate Liaison Programme continued to operate (renamed as the Partnership Group in 2006) and it established the Cambridge Corporate Gateway aiming to provide bespoke, structured programme of visits for companies outside the region to meet academics and the local business community.

The changes to the IPR policy that were initiated in the previous period led to the introduction of a new policy in 2005. This vested ownership of IP with the University rather than the academic and resulted in a period of streamlining of processes and support within Cambridge Enterprise. 
This period of consolidation also saw a number of new activities emerge as the core structures developed their modes of operation. This included a series of events targeted at building relationships with industry, research commercialisation, entrepreneurship, and supporting the high-tech cluster. The University also began to recognise the need for support to be embedded within the academic community to foster culture change and legitimisation of industrial collaborations as part of an academic career. This included the creation of department-based 'champions' coordinated by Cambridge Enterprise.

Institutionalisation (2010-present)

More recently the University has seen a growing institutionalisation and embedding of industrial collaborations and research commercialisation as core activities alongside and reinforcing of wider research and education activity. This reflects the institutionalisation of these activities as core functions of universities within the national discourse and public funding programmes. Indeed, its most recent institutional strategy for KE was in part directly informed through consultation with its core strategic large industrial partners and the network of local high-technology (most SME) firms.

Innovation and industrial engagement are now strongly embedded within the University of Cambridge and many of the core structures continue to operate and develop, not least Cambridge Enterprise and the Centre for Entrepreneurial Learning, having enjoyed almost a decade of relative stability. HEIF funding has also been used to change perceptions among the some academic staff that innovation and industrial engagement activities are not part of 'real' research, and to help develop researcher capabilities for undertaking such activities as an integral part of the whole research process.

This period has also seen major campus developments aimed at emphasising research and translation activity built around co-located partnerships between the University, industry and other core stakeholders in the process (e.g. the hospital and major publicly or charitably funded research institutes). A number of these major campus investments have been facilitated through the government's Research Partnership Investment Fund (RPIF) that also draws in significant co- 
investment from industry, including its major industrial partners. Along with other developments, this represents a fundamental shift within the University to develop two major clusters of research and translation activity, built around biomedical research in the south of the city and technology-based research to the west.

The Research Services Division was also separated into two: the Research Operations Office focusing on operational issues of day-to-day research negotiations and contracting; and the Research Strategy Office providing, for the first time, formal support to the Pro-Vice-Chancellor (PVC) for Research. Part of its remit is to facilitate the development of institutional relationships with major research funders in the public and private sectors. In addition, it is tasked with nurturing the development of collaborative, cross-disciplinary research activity, and overseeing and coordinating strategically important cross-departmental grants. Most recently in 2015, the University announced the introduction of a PVC position with the explicit and visible remit for enterprise and regional affairs. Historically enterprise activity has formed part of the research portfolio.

In Table 1, the parallel developments at the University of Cambridge and national policy levels are summarised, and in Figure 1, the level of industrial and collaborative research income over the same period is summarised. It shows the steadily growing degree of collaborative research involving nonacademic partners being secured by the University over the period of consolidation and institutionalisation $^{x \times i v}$. It also highlights the rapid rise of income through various knowledge exchange interactions with large companies (through contract research, consultancy, provision of facilities and equipment services, and workforce development courses) that is concurrent with the growing awareness of $\mathrm{Ol}$ in large firms. ${ }^{\mathrm{xxv}}$ 
Table 1: Innovation \& Industry Engagement developments at the national and University of Cambridge levels

\begin{tabular}{|c|c|c|c|c|}
\hline & $1960 \mathrm{~s}$ & 2000 & 2010 & 2015 \\
\hline & Previous Order & Experimentation & Consolidation & Institutionalisation \\
\hline 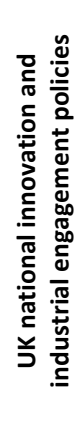 & $\begin{array}{l}\text { Government perceives } \\
\text { dual role of universities } \\
\text { to be teaching and } \\
\text { research. }\end{array}$ & $\begin{array}{l}\text { UK's New Labour Government } \\
\text { emphasizes 'Knowledge Economy' } \\
\text { and launches multiple competitive } \\
\text { funding rounds for universities to } \\
\text { set up innovation and industry } \\
\text { engagement programmes. }\end{array}$ & $\begin{array}{l}\text { National innovation and } \\
\text { industry engagement } \\
\text { funding schemes switch } \\
\text { to formula (i.e. based } \\
\text { on output metrics) } \\
\text { driven approaches. }\end{array}$ & $\begin{array}{l}\text { National agenda } \\
\text { emphasizes } \\
\text { innovation \& } \\
\text { industrial } \\
\text { engagement as } \\
\text { core mission for } \\
\text { universities, } \\
\text { positioning them as } \\
\text { key actors in } \\
\text { innovation } \\
\text { ecosystem. }\end{array}$ \\
\hline 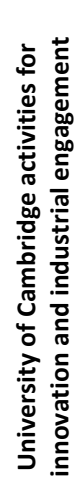 & $\begin{array}{l}\text { Innovation and } \\
\text { industrial engagement } \\
\text { activities not part of } \\
\text { core mission; limited } \\
\text { resources allocated; } \\
\text { regional innovation } \\
\text { cluster developing } \\
\text { successfully with limited } \\
\text { explicit UoC } \\
\text { engagement. }\end{array}$ & $\begin{array}{l}\text { University appoints Vice-Chancellor } \\
\text { who is ex -IBM, begins process of } \\
\text { changing IPR policies; wins funding } \\
\text { and sets up investment fund, } \\
\text { Entrepreneurship Centre, and } \\
\text { Corporate Liaison Office, and } \\
\text { consolidates technology transfer } \\
\text { functions into a central University } \\
\text { office. }\end{array}$ & $\begin{array}{l}\text { UoC consolidates } \\
\text { activities onto core of } \\
\text { Cambridge Enterprise, } \\
\text { Centre for } \\
\text { Entrepreneurial } \\
\text { Learning, Research } \\
\text { Services Division; UoC } \\
\text { develops support } \\
\text { infrastructure to } \\
\text { respond to Research } \\
\text { Councils 'impact } \\
\text { agenda'. }\end{array}$ & $\begin{array}{l}\text { Innovation and } \\
\text { industrial } \\
\text { engagement now } \\
\text { strongly embedded } \\
\text { within UoC culture } \\
\text { and systems; senior } \\
\text { management posts } \\
\text { expanded (PVCs), } \\
\text { major investments } \\
\text { in infrastructure } \\
\text { (West Cambridge } \\
\text { Campus, Biomed } \\
\text { Campus). }\end{array}$ \\
\hline
\end{tabular}

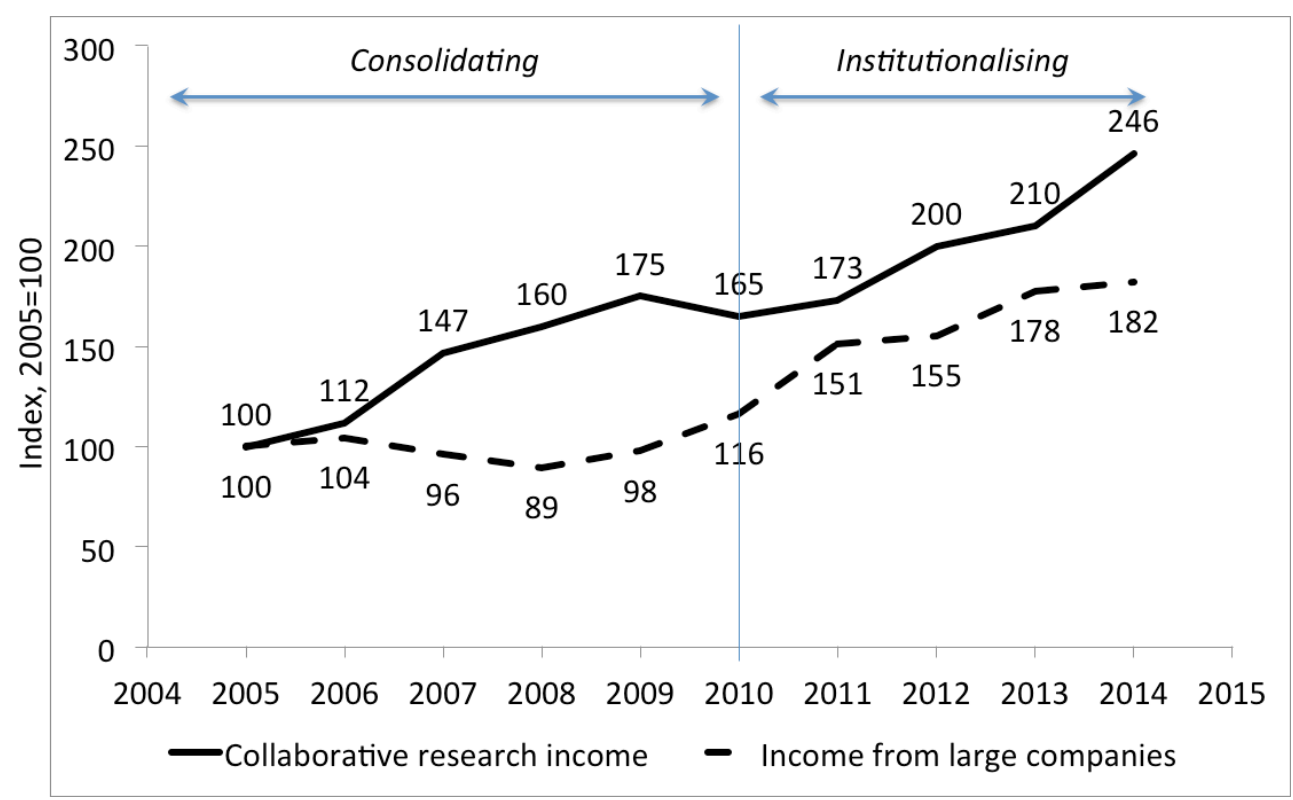

Figure 1: Income secured by the University of Cambridge through collaborative research and from large companies, $2005-2014^{x x v i}$ 


\subsection{Open Innovation implementation in industry}

During the same period as UK universities were going through major transformations in their approach to innovation and industrial engagement, firms in many industries were also undergoing substantial transformations in their approaches to innovation. Whilst the dominant paradigm for innovation up to the 1990s was for large companies to rely mainly on internal resources, during the last two decades a number of factors aligned to change the way in which companies innovate. To remain competitive in modern markets companies need to develop innovative products at a faster rate compared to the past. Demand is increasing for complex products, which require the integration of a variety of technologies. At the same time, the knowledge of individuals outside the firm has become more accessible thanks to the advent of the internet, social networking platforms, a culture of sharing, and the availability of ever more sophisticated searching algorithms. These trends have pushed companies to seek external expertise to complement internal knowledge to a higher degree compared than in the past. Concurrently, the need has emerged for companies to be able to exploit innovation through more complex and 'open' business models, accessing a number of markets and fostering future innovation in collaboration with partners.

By observing and reflecting on these trends and on the lessons provided by the examples of success and failure in leading corporations, Henry Chesbrough was able to articulate a coherent model for successfully leading innovation in modern companies: open innovation $(\mathrm{OI})^{\text {xxvii }}$. Chesbrough's OI model shows how firms should be able to access and absorb external knowledge, combine it with internal knowledge and consider a variety of potential 'outlets' for its exploitation. On one side, knowledge could enter the firm from a diverse range of sources such as other firms (including suppliers, and competitors, small and large, established or new companies), academics, and generally individuals across the board (including users and consumers). On the other side, knowledge developed internally could find successful exploitation routes beyond traditional markets outlets. For instance, it could be exploited through out-licensing or spinning out new ventures. 
The OI model was published in 2003 in a book ${ }^{\text {xxviii }}$ that became extremely popular amongst managers. The senior management of many leading firms recognised that Ol presented a solution to the diminishing competitiveness of their current innovation infrastructure and used Chesbrough's OI model as the basis for transforming their approach to innovation. P\&G was among the first and most publicly committed to developing and implementing an Ol strategy, as summarised in a declaration by their then CEO, A. G. Lafley ${ }^{\mathrm{xxix}}$. Several other companies followed suit and decided to transform their innovation processes, activities and infrastructure to follow Ol principles. In some firms, this was a 'top down' approach, with senior management clearly communicating and driving the change to Ol, whereas other can be seen to have adopted a more 'bottom up' approach, with middle managers as originators of the $\mathrm{Ol}$ initiatives, using $\mathrm{Ol}$ demonstrator projects to convince their top management.

Hence, whilst the shift towards openness in innovation has been gradual and examples can be traced back long before 2003 (see for example FIAT ${ }^{x \times x}$ ), after the publication of Chesbrough's book firms were able to draw upon an explicit model for OI implementation. Historically, firms who developed open approaches to innovation prior to the publication of the book were led by an 'effectual' decision process $^{\mathrm{xxi}}$ whereby, as a result of particular contingencies such as deep crises, many forms of OI approaches were established to help the companies survive. After the emergence of the Ol model in 2003 these firms have often identified in OI a language to describe activities already on-going. Other firms, in particular those in the Fast Moving Consumers Goods sector, have directed their efforts to establishing and deploying and OI programme, based on the model and on the examples of other firms. Thus approaches to the implementation of $\mathrm{Ol}$ can be seen as having two phases, separated by a 'discontinuity', as shown in Figure 2.

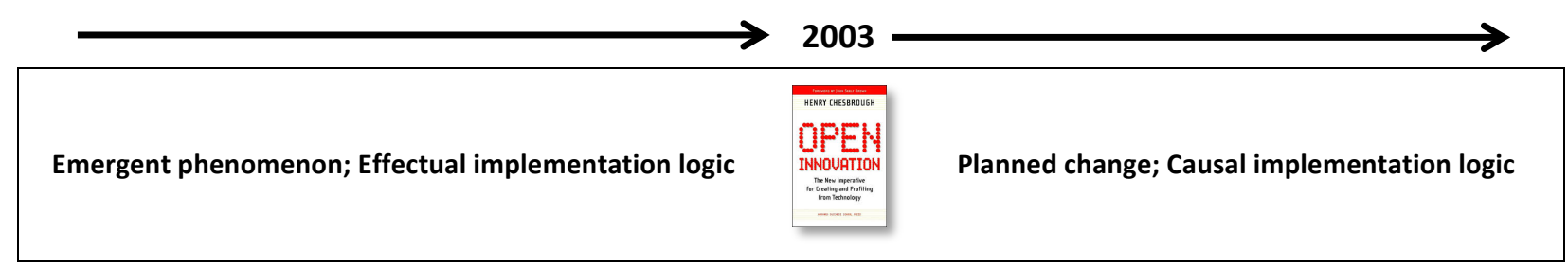

Figure 2: Changing context for open innovation implementation and the 2003 'discontinuity'xxxii 
As with the implementation of other management innovations ${ }^{\mathrm{xx} x \mathrm{ii}}$, the deliberate shift towards the OI model follows an organisational change process that entails subsequent phases: Unfreezing, moving

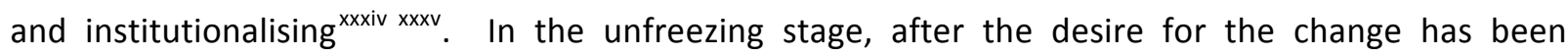
recognised, individuals are charged with guiding the transition towards the new regime or these individuals emerge because of their commitment to the proposed changes. In the moving stage, new procedures, patterns of behaviours and routines aligned with the implementation goal are setup, which often are achieved through a 'trial and error' process of learning. Eventually, the new system establishes itself as the dominant paradigm and the organisations follow a process of consolidation of the change as the new order becomes customary. This change process takes often years to be completed and firms progressively acquire the skills and the experience to 'mature' in their OI approaches $^{\mathrm{xxvi}}$.

\section{Co-evolution of parallel tracks}

The co-evolution of these tracks of activities - the national policies to support innovation and industrial engagement, and the emergence of open innovation - can be drawn together, as shown in Figure 3, with the two 'discontinuities' of the UK Government's report on 'Realising our Potential' in 1994 and Chesbrough's book articulating the Ol model in 2003 both providing pivotal moments in relation to approaches to innovation.

\begin{tabular}{|c|c|ccc|}
\hline $\begin{array}{c}\text { Context for UK } \\
\text { university- } \\
\text { industry } \\
\text { engagement }\end{array}$ & Previous Order & Experimentation & Consolidation & Institutionalisation \\
\hline $\begin{array}{c}\text { Context for open } \\
\text { innovation } \\
\text { implementation }\end{array}$ & Emergent phenomenon; Effectual \\
implementation logic & 2000 & 2010 & 2015 \\
\hline
\end{tabular}

Figure 3: Changing context of national innovation policies and OI implementation 
Within this changing context for national innovation policy and firm innovation strategy, specific cases of engagement with the University of Cambridge can be observed and we present some examples of such in the following section. The interactions occurred when firms were at different stages of the unfreezing, moving and institutionalising of their OI activities, meeting the University which was itself going through a similar process through experimentation (unfreezing), consolidation (moving) and institutionalization of its research commercialization and industry engagement activities.

\section{Case examples of co-evolution of university-industry partnerships}

Six firms' activities illustrating different approaches to engagement with the University of Cambridge over different time periods are summarised in the following section. Data underpinning these case examples has been drawn from analysis of policy and university document archives, interviews with key stakeholders, and observation from the authors' direct involvement in some of the programmes and partnerships.

\begin{tabular}{|l|l|}
\hline Firm A & Large European physical sciences firm \\
\hline Firm B & Large European ICT firm \\
\hline Firm C & Large European life science firm \\
\hline Firm D & Large European life sciences and physical sciences firm \\
\hline Firm E & Medium-sized UK technology firm \\
\hline Firm F & Large UK construction firm \\
\hline
\end{tabular}

Table 1: Case study firms

\subsection{Firm A}

From largely in-house R\&D pre-1990, Firm A has moved towards an OI approach in a number of stages.

\section{Unfreezing}

1989-1995: The first changes occurred when Firm A was reorganised and employees were encouraged to spin-off new ventures. The spin-offs became preferred suppliers for Firm A which then carried out innovation with these firms maintaining a relatively open IP policy. In this period, its partnerships with academia were largely ad-hoc, often driven by personal relationships or location. 
1995-2000: The company recognised the need to re-brand as a more sustainable business which culminated in the setup of a fund to develop a portfolio of ventures relating to sustainability as a way to explore new business opportunities.

2000-2005: Driven by a strong campaign of cost cutting, innovation and operational activities were further pushed externally to suppliers. The original strong links and trust established with the external companies started to diminish due to the retirement of the key individuals. Firm A started to explore areas of relevant science with academic institutions. They chose to establish an institute (A1 in Figure 4) at the University of Cambridge that spanned six departments, supported a number of permanentlyendowed faculty positions, as well as additional staff and a new building. The boundaries of the interaction were very broad, with Firm A committing to support the research in perpetuity without a strong model for the exploitation of the science produced.

During this period, the firm also faced strong criticism on two fronts. Concerns for the firm's safety standards following a major incident shook the leadership and led to the resignation of the CEO. Secondly, although some technology experts saw the 'relaxed' IPR policy which characterised the collaborative innovation activities with its technology suppliers as an advantage for the firm (in that it was possible to implement technologies quickly and maintain strong collaboration with partners), many stakeholders started opposing it as it was deemed too week and represented a missed opportunity to capture value.

\section{Moving}

2005-2010: The structure and trends continued in this period with the strong realisation that many of the collaborative activities with external partners (and in particular within the corporate venturing team) could be framed in terms of OI, and managers started explicitly implementing the Ol model. New partnerships were set up with academic institutions worldwide, establishing long-term research programmes that would help develop the next generation technologies that would underpin their future competitiveness. The model followed for non-UK university-industry relationships was different 
compared to that established originally at Cambridge in that it was designed to 'blend' the staff with the academics and to regulate the IP with a clear division between the 'open' and the 'proprietary' IP. During this time, the relationship with the University of Cambridge expanded and deepened beyond the original institute to other parts of the University, including the business school, and into nonresearch areas such workforce education and recruitment (A2 in Figure 4). Firm A's endowed institute at Cambridge provided a strong base from which to pursue this expansion, building on strengthening links with academics and senior university leaders, and its visibility on campus

\section{Institutionalising}

2010-2015: Trends in emerging technologies started substantially changing Firm A's core market exposing the firm's needs for reviewing the investments in technology in the longer term. The innovation model which originated in the previous years consolidated around five pillars: internal R\&D (with R\&D centres still located worldwide), M\&A, strategic partnerships and joint ventures, academic collaborations and corporate venturing activities. The latter two in particular were seen by the firm as the tools to identify and exploit innovative opportunities emerging from science and technology beyond the traditional domains. This period saw a growing emphasis within Firm $A$ on deepening its existing partnerships with universities. For technologies at an early stage, the academic collaborations worldwide encompassed under the umbrella of a distributed R\&D model ( $A 3$ in Figure 4) have expanded to include global sources of science and technology. The relationship with the University of Cambridge continued to deepen. However, growing pressures were emerging to better understand the value proposition and how to realise value from investments, including developing stronger pathways for the work undertaken within the University of Cambridge partnership into the firm's R\&D effort to support their short, medium and long term innovation objectives. Strong working relationships have been built up over the past decade, both between individual academics and scientists, as well as at senior management levels. These trust-based relationships importantly helped to foster a culture of learning about how best to work together towards mutually beneficial objectives and ensure that both organisations benefit from the relationship. 
For more mature technologies the firm relies on its corporate venturing arm to explore projects in emerging areas of interest which has, since 2009, moved the traditional focus on widely explorative strategies to encompass ventures relating to the current firm's markets.

\subsection{Firm B}

By the start of the 1990s, Firm B market had moved from its wide base in a diverse range of industries to concentrating on information and communication technologies (ICT). Its historical growth strategy based on M\&A was substituted by a focus on organic growth.

\section{Unfreezing}

1996-2002: Firm B managed the transition across major shifts in ICT paradigms through intense collaboration with other companies in the industry aimed at developing new standards. When a further technology shift in technology emerged, Firm B collaborated with competing firms on the joint development of a commonly accepted and more open set of standards. This activity was very successful and the firm managed to exploit the new technology paradigm becoming mid 90s one of the world's largest companies in the sector.

\section{Moving}

2002 -2007: A new strategy was focused on launching diversified products whilst reducing costs per products. This was pushed by a dual pronged strategy: cutting available R\&D funds as well as identifying, capturing and successfully exploiting new standards. Firm B established an external technology scouting team to speed up new product development. The scouting activity had the aim of identify the promising technologies and scouts were motivated via financial incentives against measures such as "on time to market" and "delivery of important components". At the same time the firm started reducing available funds for the internal development of new components encouraged people to look outside for new technology quickly implementable. The same pressures encouraged the spinout of research teams who worked as technology suppliers. Plans were developed to establish 
a technology forum as a platform to bring business, R\&D and suppliers together and the company started to work intensely with universities for developing the next technological generation of ICT products.

\section{Institutionalisation}

2007-2011: This period saw a major transition in Firm B's sector. Firm B pursued this new market via collaboration with and later acquisition of a company that had developed software that had the potential to be the dominant standard in the new technological era. Alongside this strategy the company decided to set up research centres worldwide in partnership with key research institutions (mainly universities) to develop long-term future technology-underpinned options. University collaborations were also seen as an opportunity for Firm B to transform itself away from a mainly product to a more product-service oriented firm. These collaborative international research centres were tasked with helping Firm B identify and lead the next technological revolution. These research centres became a separate unit within Firm B, not attached to any one of the specific product development business units. The research centre at Cambridge focused on materials and was based on previous successful interactions with the university groups through funding of individual research projects (B1 in Figure 4). Firm B's focus primarily lay on inflows of knowledge, and the research centres formed very few spin-offs. The centres worked to establish new technological platforms to be used externally. OI was treated in the same way as internal innovation and was expected to deliver against a common set of criteria. The model was based on co-location and co-creation with core teams made up of Firm B's researchers and academics to set the research agenda, manage the cocreation challenges (e.g. intellectual property, co-creation flows) and set up appropriate governance mechanisms that enhance Firm B's cultural understanding of its partners. Firm B's research centres published newsletters on the meaning and application of OI clarifying the basics of IPR for external collaborators to engage with them. 
2011 - 2013: As it became clear that Firm B's new technology platforms for its core business had lost the battle to be the industry standard, the bulk of Firm B was acquired by one of its competitors who held a competing standard. Firm B's technology centres did not form part of that acquisition, and have continued to operate in collaboration with other partners.

\subsection{Firm C}

Firm $C$ is a large multinational company in the life sciences industry, with operations world-wide.

\section{Unfreezing}

1990s - 2005: The 1990s saw rising industry-wide challenges in the prevailing model of drug discovery, with dramatically rising costs and declining R\&D productivity. This period also witnessed the emergence of new technologies that were likely to shape future products. These required fundamentally new capabilities and competences to be developed. In addition, the technologies were becoming ever more complex. Firm C, as with others in the sector, was faced with an urgent need to rethink how it innovated, both in product and process. Firm $\mathrm{C}$ has a long history of funding major research activities in universities. At the University of Cambridge it had invested in a major long-term research institute in the early 1990s (C1 in Figure 4) in the expectation that it would lead to fundamental advances in their product innovation efforts as shifts in the industry took hold. The formation of the institute emerged via strong personal relationships between a senior Firm C executive and a senior Cambridge academic who recognised the value industry had to play in academic research. Progressive for its time, the investment involved co-locating Firm C scientists with an embedded lab in the Department of Chemistry, a strong focus on collaborative working between University of Cambridge and Firm C's researchers, and significant investments in the upgrading of research facilities. Firm $\mathrm{C}$ owned the emerging IP, but the collaboration agreement meant that Cambridge would receive royalties from any commercialised outputs. In addition, the University had the right to ask for a reassignment of the patents back, free of charge, if the company did not exploit them. The investment, however, was not renewed in 2002 as a different approach to the next phase 
of product development. Nevertheless, the facilities remained in place within the University as did many strong individual relationships and a clear understanding between Firm C and the University of each others' organisation.

At the same time, faced with the major industry-wide shifts of the early 2000 s, Firm C realised that it no longer had the internal capabilities and competences to develop world-leading products by relying on these alone and started looking for partnerships outside. However, early forays into opening up their innovation process to external organisations to support product development were challenging. Nevertheless, those involved in the process within Firm C learned a lot about both the potential benefits - but also the pitfalls - of externalising R\&D and innovation-related activities.

\section{Moving}

2005-2012: The mid-2000s saw the arrival at Firm C of a new senior executive from academia tasked with transforming Firm C's R\&D model. The new executive came from a different culture, with a different approach to R\&D, and with a different set of capabilities to what existed within Firm C. He quickly recognised the need to fundamentally change the R\&D model to address a number of the industry-level shifts affecting the way products were being developed, as well as the highly routinized approach to innovation that had come to dominate the company. The focus was to develop a more distributed - and global - network of innovation partners to mitigate some of these risks of overreliance on a small number of external partners. Hence, the R\&D configuration moved towards smaller, multidisciplinary and nimble teams. The number of layers between management and lab scientists was dramatically reduced and teams were provided much with greater autonomy. These changes partly aimed to recreate internally the entrepreneurial spirit and environment that characterised the many innovative smaller firms within the sector. The reforms to the R\&D model saw a much greater focus on developing stronger, collaborative links with key knowledge partners including universities and other publicly funded research institutes. Ol approaches were gradually embedded in its divisions, with a new business model developed including its IP policy to guide the 
sharing of collaborative outputs encompassing a shared risk, shared reward model also for partnerships with academic universities. In return, the academic partner would stand to benefit financially should the product succeed. Firm C also recognised during this time that it lacked the internal capacity to fully exploit the vast amount of data generated over its history internally. To address this, it began to experiment in organisational models that opened up its internal resources to the academic community and developing co-located lab-space for visiting scientists from academic and other publicly funded research institutions. It also began to open up its world class facilities, recognising that academia often lacked these facilities which could improve their ability to focus their research activities and strengthen the commercialisation potential.

The relationship between the University of Cambridge and Firm C was rekindled in 2008 with the signing of a collaborative agreement as part of the company's new 'academic incubator' concept (C3 in Figure 4), led by a Cambridge lifescience department. The new relationship enabled professionals and academic institutions to become directly involved in, and help optimise the early product development of compounds originating either within Firm C or academia. Their renewed relationship reflected Firm C's, 'shared risk, shared reward' approach with Cambridge providing its know-how and expertise as well as bearing some financial risk, and the company providing operational support, access to in-house research and facilities and critical background data. Cambridge was to be compensated should commercialised products emerge. The re-emergence of this relationship built upon strong individual-level links maintained from the earlier period as well as the presence on campus of a unit established in 1999 (C2 in Figure 4). The co-location of this unit, with its director being a joint appointment between Firm $\mathrm{C}$ and Cambridge, meant a strong, local presence on campus with strong ties into the clinical school.

\section{Institutionalising}

2012-2015: The company continued to develop its R\&D model fully embedding elements of open innovation working with academic and research institutions worldwide. A team was appointed in 2013 to manage the technology and innovation activities and coordinate the links with partners to make its 
R\&D organisation more agile and entrepreneurial, embedding a culture of pursuing the best scientific opportunities whether internal or external. To facilitate co-location, it developed a science park on its own R\&D campus (C4 in Figure 4), providing space not just for new start-ups in relevant technology and product domains that could feed into their R\&D pipeline, but also to universities and competitors. Key individuals within Cambridge recognised the value of developing deeper, more strategic linkages with Firm C, reflecting the changing landscape at the University. Concerted efforts were made by senior academics to foster this relationship, building on the already strong links between individual researchers and groups. Cambridge was the first university to establish research and translation space on the co-located science park, with a number of researchers based onsite, away from their traditional home within the University.

\subsection{Firm D}

Pre-dating the implementation of Ol, a joint research institute based around chemical informatics (D1 in Figure 4) had been established at Cambridge. This was regarded as something of an anomaly within the broader R\&D activities of Firm D, which had donated funds for the setup and first five years of operation with the potential for further longer-term funding. Firm $D$ had relatively loose relationship with the institute, simply committing to encourage cooperation between scientists.

\section{Unfreezing}

2006-2008: As its main competitors publicly committed to transforming themselves using OI, Firm D also decided to embrace OI with the expectation of achieving a higher innovation rate and reducing $R \& D$ costs. The shift to OI was supported internally by a senior manager (VP for R\&D in one of the business units) who appointed a small team of R\&D managers across the firm's two main business units to implement OI practices across the firm (to establish processes and develop skills in the workforce across the two business units). 
Part of the plan involved the transformation of Firm D's corporate R\&D laboratories in the UK into an 'Ol campus'. The transformation was intended to keep the research capability and equipment inhouse and at the same time attract external knowledge from local universities and co-located startups. For this plan, the interaction with established knowledge institutions in the region was fundamental to also ensure that the regional development agency would co-fund the initiative with public money. With this aim, the Firm D manager overseeing this initiative established a new connection between Firm D and University of Cambridge. The connection was embodied in a small sponsored research project involving the firm's OI managers and a group of researchers at two departments at the University of Cambridge (D2 in Figure 4).

\section{Moving}

2008-2012: Firm D appointed a director for OI in 2008 who took over the activities of the original OI implementation team, several of whom had since either left the company or changed roles. The new, more formalised $\mathrm{OI}$ team dedicated itself to refining the processes and procedures of $\mathrm{OI}$ and, through several experiments, to consolidate, scale-up and diffuse them throughout the organisation. Amongst these activities was the establishment of a framework for cooperation with universities. This implementation of this framework was carried out by a liaison officer from Firm D who dedicated himself to designing a model of collaboration with key institutions. At this time, the formal relationship with Cambridge was interrupted, though some direct interaction between some of the most junior operational OI managers and the academics remained.

\section{Institutionalising}

2012-2015: A model of collaboration with universities was developed and tested with the establishment of key collaboration frameworks with some institutions. This model saw the formation of mixed university centres where people from both institutions could work side by side covered by an umbrella agreement. The idea was for these centres to provide the firm with knowledge and the opportunity to keep up to date on particular strategic scientific areas, whilst a budget for ad-hoc 
collaborations with other institutions was also created. Attempts by Firm $D$ to implement this more structured model with the University of Cambridge were initiated in 2012 but the negotiations did not come to fruition (D3 in Figure 4).

\subsection{Firm E}

In the early stages of this Firm E's history, it fought and won a high profile battle with a major multinational for patent infringement. As a result of this, the firm was extremely sensitive about matters of IP protection and had a clear policy not to engage with any external partners. For much of its history, all innovation activities were managed on an extremely closed basis.

\section{Unfreezing}

2005-2011: Once the company had achieved quite significant commercial success, it began to explore opportunities to engage with universities from the mid-2000s onwards. They gave an R\&D manager the explicit role of external engagement and began exploring opportunities to collaborate with Cambridge and other universities.

\section{Moving}

2011-2014. In 2011 the decision was taken to fund two PhD students in one department at Cambridge, and for a representative of the company to have an office located in the same department to explore opportunities for further collaboration across the university (E1 in Figure 4). The firm's perception of the quality of students attracted by this funding led to the funding of a professorial chair at the same department. The University was able to manage the IP negotiations speedily by using - at the request of the firm - a template of an existing framework agreement from another long-standing partnership with the same department.

Within three years of the initial funding of the research students, the decision was taken to provide a substantial endowment to fund the construction of a new building (E2 in Figure 4) and the development of a new laboratory within the same department. Firm $E$ has also since made 
endowments of a similar scale at another UK university. The firm went through the transformation from very closed to targeted open innovation activities extremely quickly. In terms of drivers for their engagement with Cambridge, the firm highlighted the existence and perceived success of the university's long-standing partnerships with leading firms.

Though Firm E's progress from closed to collaborative R\&D has been rapid, it is not yet clear that they have fully institutionalised the transformation to OI.

\subsection{Firm F}

Firm $\mathrm{F}$ operates in an industry that is typified by relatively low levels of innovation and high resistance to change. The founders of this privately-held firm made the decision in the late 2000 s to attempt to drive change in the industry through collaborations with several UK universities.

\section{Unfreezing}

2009-2011: Having made the decision that a step-change in approaches to innovation was needed, Firm $\mathrm{F}$ moved rapidly to establish a series of partnerships with UK universities, including Cambridge, based around specific technology domains. At Cambridge, funding was provided for an endowed professorship, the launch of a Masters degree programme, executive education and research activities (F1 in Figure 4). Firm F wanted things to move extremely rapidly, and as Cambridge now had in place systems and staff appropriate for managing complex and large scale negotiations, and could draw upon equivalent deals agreed with other organisations, the deal was signed in 2010 with activities launched in 2011.

\section{Moving}

2011-2015: Firm F has developed a network of research collaborators based around different technology domains and has, in parallel, developed its own large-scale R\&D facilities. These internal facilities are intended to allow ideas developed within small-scale university labs to be scaled-up and assessed for suitability for application. The firm has also used its engagement with Cambridge to 
develop what it perceives to be potential 'rising stars' within the company by sending them to attend educational programmes at Cambridge tailored for their needs, but which allow interaction with delegates from a range of different companies and sectors. Firm F's hope is that by these 'change agents' learning and transferring new approaches, the firm's approach to innovation will be transformed.

As with Firm E, Firm F's progress from closed to collaborative R\&D and innovation has been similarly rapid, it is also too early to see whether they have fully institutionalised the transformation to OI.

\section{Discussion}

Evidence from the six cases can be structured as in Table 2, positioning each within the firms' phase of Ol implementation against the phase of approach to innovation and industrial engagement at the University of Cambridge at the time of the industrial partners' first major Ol involvement. Figure 4 summarises the cycles of the university and the partners and the dates of the major collaborations.

The majority of the collaborations were setup with the intention of allowing the firms to embed within the university facilities ("Go to key places" strategy). In some examples the engagement with the university was aimed at creating an infrastructure within the firms' facilities where academics and companies could mingle ("Come to me" strategy). 
Figure 4: The cycles of implementation of the University of Cambridge with each of the partners and the dates of their most significant agreements

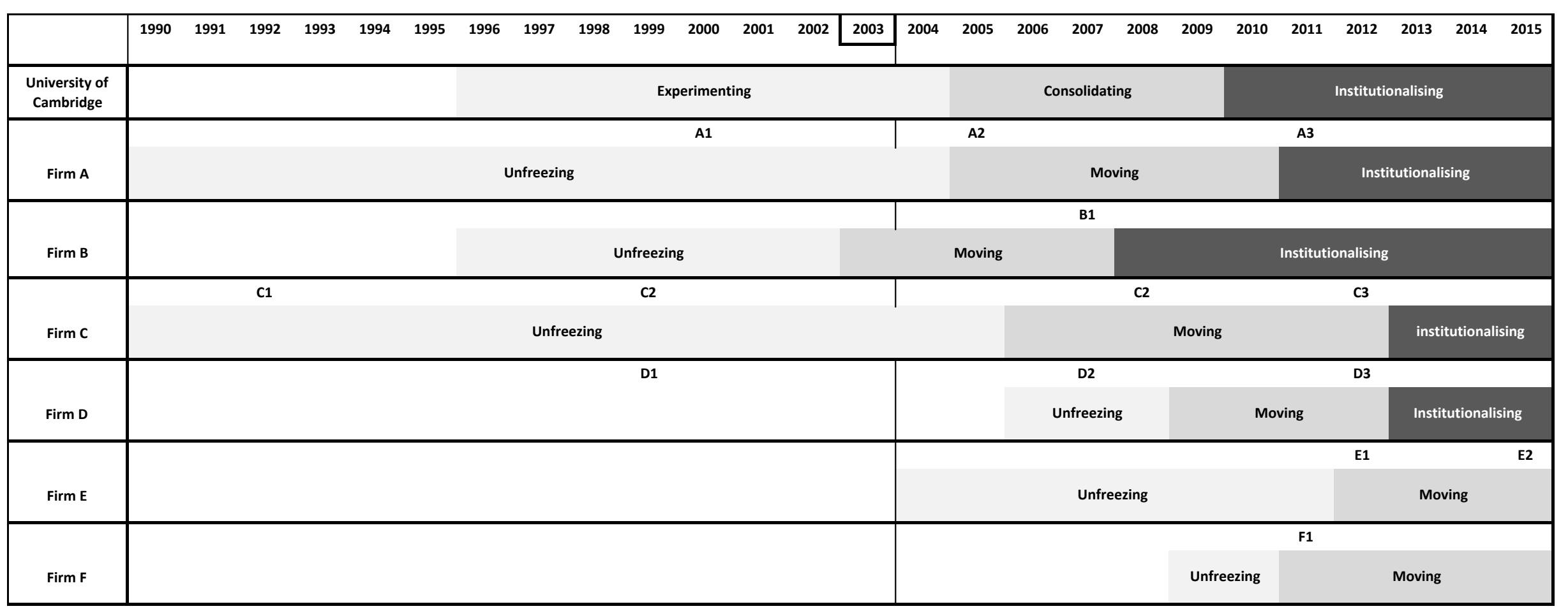


Table 2: The collaborations established by University of Cambridge with large corporations

\begin{tabular}{|c|c|c|c|c|}
\hline & \multicolumn{3}{|c|}{ Phase of innovation and industry engagement support (UoC) } \\
\hline & & Experimentation & Consolidation & Institutionalization \\
\hline \multirow{3}{*}{ 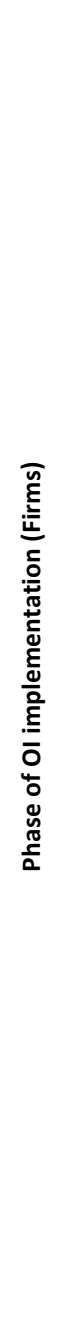 } & 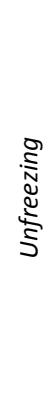 & $\begin{array}{l}1 \\
\text { 'GO TO KEY PLACES' } \\
\text { Major investments to create large, co-located research } \\
\text { institutes within the University premises. Mostly undefined in } \\
\text { terms of processes for realizing value. There is a general } \\
\text { expectation that 'good things' will flow from excellent research } \\
\text { (A1,C1,C2,D1). }\end{array}$ & $\begin{array}{l}\text { 'COME TO ME' } \\
\text { Part of D's OI implementation plan involved transformation of } \\
\text { former corporate R\&D labs into 'Ol campus' (D2). Funding } \\
\text { research via engagement with UoC enabled collaborative } \\
\text { activities and the leveraging of public funding for the R\&D lab } \\
\text { transformation. The connection is established only for a limited } \\
\text { time, through a research project. This engagement model does } \\
\text { not provide the required foundations to scale up the } \\
\text { engagement across the two organisations in the face of } \\
\text { employees turnover in the stages of reorganisation. }\end{array}$ & \\
\hline & $\begin{array}{l}\stackrel{\text { ? }}{s} \\
\text { o }\end{array}$ & & $\begin{array}{l}3 \\
\text { 'GO TO KEY PLACES' } \\
\text { Firm A extended the relationship to stretch beyond the } \\
\text { confinements of the traditional science topics covered by the } \\
\text { A1 into new disciplines and non-research activities (A2). } \\
\text { Firm C formed deeper relationship with UoC facilitated by the } \\
\text { maintenance of strong individual-level relationships developed } \\
\text { in previous periods, despite the demise of institution-level } \\
\text { investments (C3). }\end{array}$ & $\begin{array}{l}5 \\
\text { 'GO TO KEY PLACES' } \\
\text { Firm E were able to rapidly scale-up significant engagement as } \\
\text { they both had clear OI strategies, and UoC had developed } \\
\text { appropriate culture, operations and precedents to support } \\
\text { them (E1, E2). } \\
\text { F had decided to break ultra-conservativeness of construction } \\
\text { industry by engaging with UoC. This was very new to F but UoC } \\
\text { was able to work with them and to establish a Chair, research } \\
\text { programme/centre \& Masters' course (F1). }\end{array}$ \\
\hline & 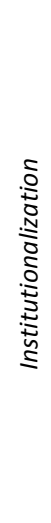 & & $\begin{array}{l}4 \\
\text { 'GO TO KEY PLACES' } \\
\text { B developed concept of embedded research centres within } \\
\text { universities (B1), and had clear sense of capabilities required } \\
\text { and where these could be accessed. The collaboration between } \\
\text { the two organisations was already happening through } \\
\text { cooperation in specific programmes. For UoC, B's area of } \\
\text { scientific interest was focal point and B provided resources to } \\
\text { support infrastructure development, when public funding was } \\
\text { limited and later to attract more industrial partners. }\end{array}$ & $\begin{array}{l}6 \\
\text { 'GO TO KEY PLACES' } \\
\text { A's Distributed R\&D approach (A3) focused on deepening and } \\
\text { expanding relationships with UoC, and a particular emphasis on } \\
\text { developing stronger pathways to realise value arising from the } \\
\text { investments. Key elements were managers appointed as } \\
\text { gatekeepers to maintain and expand the relationship between } \\
\text { the two organisations at the individual level. } \\
\text { 'COME TO ME' } \\
\text { C's followed a similar model compared to D, attracting } \\
\text { investments from public funding to create a campus within the } \\
\text { premises of their R\&D facilities (C4). The universities in the } \\
\text { local area have been involved (including UoC) as well as a } \\
\text { number of other companies. }\end{array}$ \\
\hline
\end{tabular}




\subsection{University of Cambridge - Experimentation phase}

Several collaborations were established by University of Cambridge with large firms in the late 1990s. These collaborations typically emerged from the direct interaction between individuals in the University and figures of power and influence within the firms. However the setup of the early stage collaborations in many cases did not express a deliberate attempt for the firms to exploit the knowledge created through these partnerships. These are rather seen as opportunities to explore scientific areas together that might, in the long-term, generate important scientific discoveries and hence provided benefits. The environment at Cambridge is characterised by multiple new programmes and organisations, often run by staff who were themselves new to the University, with rules and procedures in a state of flux. The existence of groups dedicated to supporting industrial engagement - even if somewhat rudimentary - provided a means for firms to establish a foothold in the University, and then evolve their engagement as needs changed. However, although data about 'failed' events were not collected, it is possible that several agreements between firms might have fallen through as a single point of contact with influence in the university was difficult to identify. Multiple possible entry points existed, each of which offered a slightly different service (e.g. support for technology transfer, identification of partnership opportunities, networking events, engagement with spin-outs, et al.). As many University groups and activities were funded with money that had been competitively awarded against the delivery of specific targets, this at times drove some quite blinkered behaviour in the pursuit of these targets.

\subsection{University of Cambridge - Consolidation Phase}

During the consolidation phase, the University was more focused on developing its long-term strategic partnerships and was targeting its limited resources around activities that would support the setup and management of such connections. This coincided with the shift of public funding away from competitive bidding for support for specific programmes, to an institutional level award, the scale of which was determined by institutional-level metrics. As the cycle of implementing OI for industry 
became more dominant we observed three types of situations for the University when they partnered with:

1. An unfreezing firm (e.g. D) who had the objective to embed the University within their evolving R\&D infrastructure (D2). For this goal it was important to attract the University in their location. Re-locating the institute (D1) established many years earlier within the University to Firm D's R\&D campus was not possible, as many of the academics had relatively weak links with the firm and had no incentive to move. However, Firm D found other academics within the University interested in collaborating and a capable team of industry-experienced administrators who could swiftly establish an agreement for a sponsored research project (D2) that provided Firm D with the OI-related engagement that they needed.

2. Moving firms (e.g. A and C) who reviewed their previous collaborative setups to extend them beyond the original boundaries. By leveraging established relationships, it was possible for them to establish new protocols of interaction that encompassed a stronger framework for the exploitation of the knowledge produced through the partnership with universities.

3. An institutionalising firm (e.g. B) with the idea of externalising the blue sky R\&D and creating a network of distributed research centres. Firm B built upon past collaborations with academics who had run a series of smaller past research projects that were perceived by the firm to have been successful. Cambridge had in place the core elements of its increasingly strategic approach to industry engagement and infrastructure development, and could see a clear fit with hosting one of Firm B's collaborative research centres.

Our cases revealed how, during this phase, companies at different stages of Ol implementation benefited from having access to centralised support services within the University - often staffed by ex-industry managers with academic backgrounds - that were able to meet diverse individual department- and academic-level requests. However, attempts to systematise industrial engagements were not always welcomed; tensions between the desire of some academics to 'protect' their own corporate contacts, versus the desire of a centralised groups to manage these links was evident in 
some instances (D1). Firms that were successful at during this phase were those that were able to balance engagement with the sometimes-perceived overly-rigid requirements of central administration with on-going and more flexible relationships with individual academics and groups.

\subsection{University of Cambridge - Institutionalization Phase}

During the institutionalization phase, innovation and industrial engagement have become a core feature of the culture of the University, and there are robust and appropriate support systems in place. The University and its academics are increasingly receptive to exploring non-traditional, experimental approaches to collaborative working with industry, providing it remains within boundaries of the pursuit of scientific excellence and its translation into use. Our cases encompassed two different circumstances:

1. For the privately owned companies (e.g. E and F) at the early stages of moving towards an open approach to innovation that meant the opportunity to find fertile ground to evolve quickly to establish infrastructure and people within the University (research centres, courses, chairs, dedicated laboratories). The Cambridge culture and systems now provided means by which activities ranging from the small-scale, experimental programmes to major capital investments can be implemented, and the rapid scale-up along the continuum of engagement modes is possible. This culture and system means that the University is able to work with partners at all stages of $\mathrm{Ol}$ implementation maturity. This can be seen in $\mathrm{E}$ and $\mathrm{F}$ who have made substantial, and rapidly-scaled engagements with the University despite each being at different stages of $\mathrm{OI}$ implementation maturity. From our analysis, key enabling features of the system is the availability of precedents (i.e. both visible role model examples and contractual procedures that can be readily cloned), the ability to manage engagements across multiple University departments, and tangible benefits beyond core research collaborations (e.g., engagement with the regional innovation ecosystem, student recruitment). 
2. For the institutionalising firms such as $A$ and $C$ the ground is fertile to deepen previous relationships with the university. For A, who follows the "Go to key places" model there is the opportunity for further embedding within the network of the University and establish key gatekeepers between the firm and academics. The action of these gatekeepers has the benefit for the university to provide connection across its departments. Firm C found the University inclined to support the participation in an external science park as its commitment to demonstrating the impact of research increased.

We observed sharing and peer learning among representatives of firms collaborating with Cambridge on a range of Ol practices. We observed how some of these experiences, in turn, were disseminated back through to the wider $\mathrm{Ol}$ activities of the corporate parent via boundary spanners ${ }^{\mathrm{xx} x \mathrm{vi}}$. Of particular interest was the way in which some experiences did become embedded in the 'corporate memory' while others did not. This was due, in part, to the 'churn' in key staff as corporate structures and roles changed in response to the stage of evolution of Ol implementation.

Hence, to summarise, the key trends observed were:

'Go to key places' model:

1) Firms who started embedding historically did it ad hoc, yet with major investments driven by belief that academic research would lead to commercialisable benefits for the company (e.g. Firms $A, B, C)$ and then progressively increased their integration and revisited the interaction and ownership frameworks. They followed the processes and opportunities of scaling up the interaction alongside the cycle of institutionalisation of industry engagement and innovation within the University.

2) Firms such as $E$ and $F$ who started engaging when the University was already fully receptive and setup for an interaction, could very quickly scale up the cooperation programmes. This could be a result both of their particular ownership configuration (e.g. private-owned) and because of the 
possibility of learning from a model which had already been implemented - very visibly - by many other companies and which the university now was fully supporting.

'Come to me' model:

1) Attempts by Firm $D$ to engage Cambridge in the setup of an Ol campus away from Cambridge (D2) at the onset of firm's Ol reorganisation did not have buy-in from senior academics. The lower collaboration maturity levels of both organisations resulted in a collaboration (based on smallscale contract research) that was not sufficient to maintain the collaboration in the long-term interaction through changes of management and the subsequent formalising of OI relationships with key partners.

2) An attempt by Firm C to do something very similar when both organisations were at a higher level of maturity resulted in engagement and commitment from both the top of the firm and the University, as there was clear alignment of objectives, and appropriate systems in place to allow this to be executed.

From this analysis some generic observations can be made, as structured in Table 3, which can be used to provide support for managers in universities and companies who are seeking to establish partnerships. 


\section{Table 3: Summary of key phase-related issues}

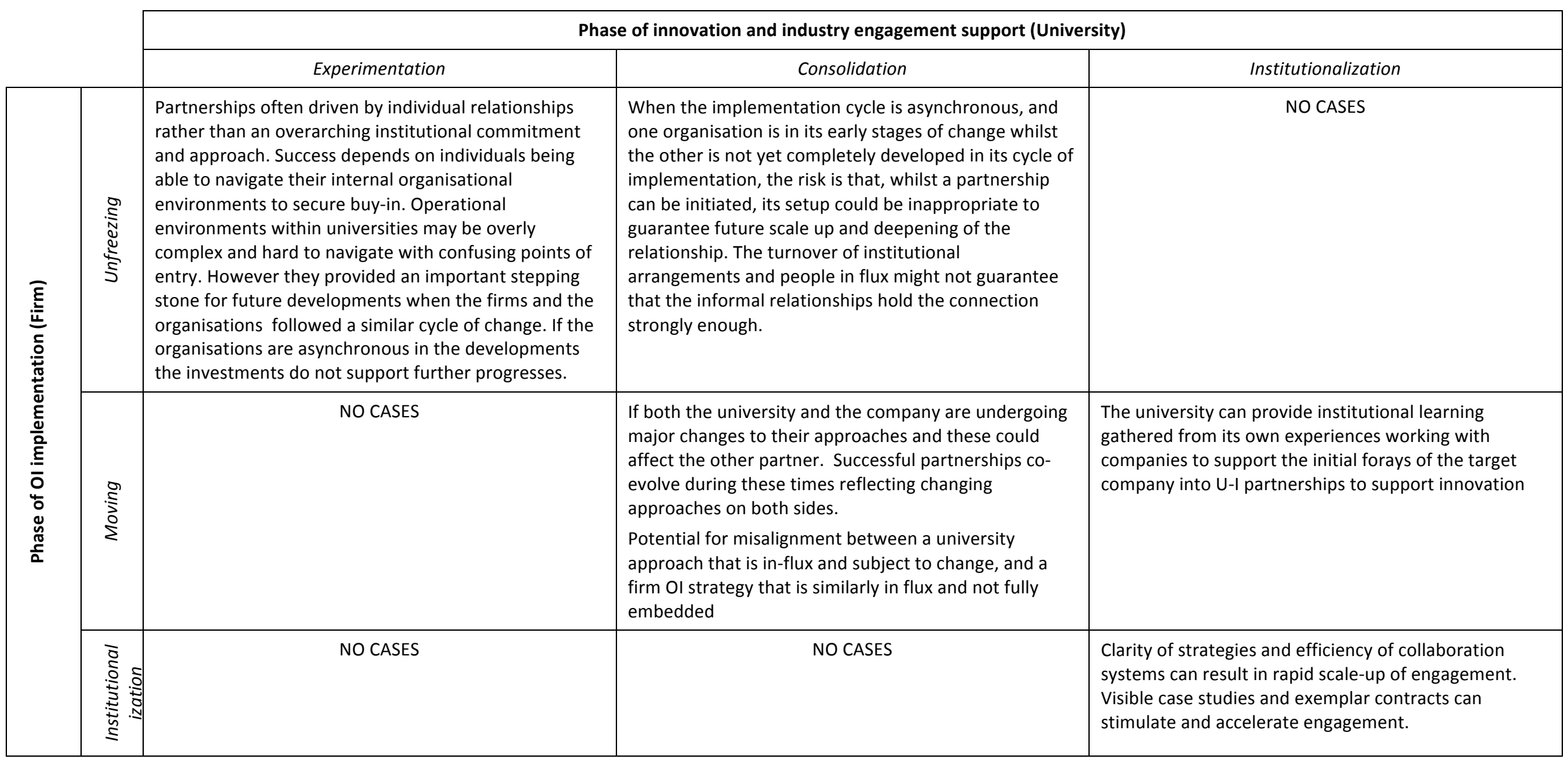




\section{Conclusions}

Partnerships between firms and universities have become increasingly more important and sought by both types of organisations over the past 20 years. This period has seen universities become increasingly important components of science and innovation policies in the UK and elsewhere, with growing pressures from government and industry for them to become increasingly strategic actors in processes of innovation and economic development.

In parallel, trends in industry have pushed companies towards establishing OI processes, in particular since Chesbrough defined a specific and accessible OI model in 2003. In this context, firms are seeking collaboration with universities as these represent an opportunity to develop new knowledge in adjacent fields, at a lower cost compared to establishing and supporting internal R\&D facilities.

Both organisation types have been through a process of change that encompasses three stages: unfreezing, moving and institutionalisation of the changes. For universities in the UK, these stages have been driven by an evolving policy context and associated public funding streams, as well as the inclusion of considerations of impact into both project-level and university-level research funding decisions. At the same time, universities are better understanding the benefits of working collaboratively with industry to address innovation challenges, and the processes required to make this work. For firms, a range of industry- and firm-specific issues has driven their progress through the stages of OI implementation.

This paper has analysed the relationships of one UK-based research-intensive university with a number of leading multinational firms at different points along parallel processes of organisational development. From this, we have identified approaches used and problems encountered at different stages, and drawn lessons that can support corporate and university decision makers in establishing and managing successful partnerships.

Some key concluding observations: 
Presented at the $2^{\text {nd }}$ Annual World Open Innovation Conference, Santa Clara, 19-20 ${ }^{\text {th }}$ November 2015

- Companies need to understand the stage of evolution of a potential partner university when seeking to form collaborative relationships to support their OI activities. Universities that have institutionalised their approaches to industrial engagement will likely be able to respond more rapidly and effectively to approaches by companies to build innovation-driven relationships. Companies approaching universities in earlier phases of their development will likely have to identify key individuals within the university at appropriate levels of seniority to help them navigate the organisation and drive the negotiations forward.

- Prior relationships with a university can be important for helping companies to broaden and deepen their engagements with a university not least through the understanding of each others' cultures, objectives, and organisational and social networks.

- Institutional, rather the just key individual, commitment and buy-in from both sides appears to be important, particularly where models of engagement being implemented are not incrementally innovative, but a step change for one or both of the partners.

The study also points to some key areas of further research:

- This work focused on the development and experiences of a globally leading research university in which the balance of power between the centre of the university, its departments and individual academics is skewed heavily towards the latter. It would be instructive to extend the case to explore other types of universities with different missions, research portfolios and balances of power between central leadership, departments and academics. This would allow us to examine the extent to which our findings can be generalised to other types of universities.

- Further research is also necessary to trace specific pathways of influence in each of the cases, between the company leadership and managers involved in developing and implementing $\mathrm{OI}$ strategies, through the partnership with Cambridge and the leadership and academics within the University involved in developing approaches to industrial engagement (and vice-versa). It would be instructive to attempt to disentangle the effects of the progression of the general 
Presented at the $2^{\text {nd }}$ Annual World Open Innovation Conference, Santa Clara, 19-20 ${ }^{\text {th }}$ November 2015

recognition of the benefits afforded to universities and companies through closer

engagements with each other, and the influences of companies and universities on each other

through specific relationships.

- Further cases could be added to explore those that failed to materialise during each of the

periods of University's transformation. This activity will support the building of a more

complete map of the co-evolving paths of the implementation cycles.

\footnotetext{
i Lewin, K. 1947. "Frontiers in group dynamics." Human Relations 1:5-41.

ii Hughes, A., Kitson, M. (2012). "Pathways to impact and the strategic role of universities: new evidence on the breadth and depth of university knowledge exchange in the UK and the factors constraining its development." Cambridge Journal of Economics 36, 723-750. doi:10.1093/cje/bes017; Deiaco, E., Hughes, A., McKelvey, M. (2012). "Universities as strategic actors in the knowledge economy." Cambridge Journal of Economics 36, 525-541. doi:10.1093/cje/bes024

iii Youtie, J., Shapira, P. (2008). "Building an innovation hub: A case study of the transformation of university roles in regional technological and economic development." Research Policy 37, 1188-1204. doi:10.1016/j.respol.2008.04.012; Breznitz, S.M., Feldman, M.P. (2012). "The engaged university." The Journal of Technology Transfer 37, 139-157. doi:10.1007/s10961-0109183-6; Hughes, A., Kitson, M. (2014). Connecting with the Ivory Tower: Business Perspectives on Knowledge Exchange in the UK. Cambridge, London: UK Innovation Research Centre; Perkmann, M., Walsh, W. (2007). "University-industry Relationships and Open Innovation: Towards a Research Agenda" International Journal of Management Reviews 9 (4): $259-80$. doi:10.1111/j.1468-2370.2007.00225.x.

${ }^{\text {iv } H M S O}$ (1994) Realising Our Potential: A Strategy for Science, Engineering and Technology, London: HMSO

${ }^{v}$ Knowledge exchange is defined here as those direct interactions that form between universities and external partners to transfer and exchange knowledge that go beyond the traditional academic activities of scholarly publication and the production of an educated labour force.

${ }^{v i}$ Howells, J., Nedeva, M. Georghiou, L. (1998). Industry-Academic Links in the UK, a report by the Policy Research in Engineering, Science \& Technology (PREST), University of Manchester to the Higher Education Funding Council for England, HEFCE ref 98/70; Lambert, R. (2003). Lambert Review of Business-University Collaboration, London: Her Majesty's Stationery Office; Hughes, A., Moore, B., Coates Ulrichsen, T. (2011). "Evaluating Innovation Policies: A Case Study of the Impact of Third Stream Funding in the English Higher Education Sector", in eds (Colombo, M., Grilli, L., and Piscitello, L.) (2011) Science and Innovation Policy for the New Knowledge Economy, (PRIME Series on Research and Innovation Policy in Europe), Cheltenham : Edward Elgar

vii Lambert (2003), op. cit.

viii Howells et al. (1998), op. cit.

${ }^{\text {ix }}$ The main funding schemes included the Higher Education Reach Out to Business and the Community (HEROBC) to help build the capability within universities to engage with industry; the Science Enterprise Challenge (SEC) Fund supporting the creation of a network of university centres specialising in the teaching and practice of commercialisation and entrepreneurship; the University Challenge Fund (UCF) creating seed funds to support early stage technology ventures; and the Higher Education Active in the Community Fund (HEACF) to support community engagement activities.

${ }^{x}$ Lambert (2003), op. cit.

${ }^{x i}$ Lambert, R. (2003). Lambert Review of Business-University Collaboration, HM Treasury.

xii Sainsbury, D.J. (2007). The Race to the Top: A Review of Government's Science and Innovation Policies. London: Her Majesty's Stationery Office

xiii Research Partnership Investment Fund (RPIF)

xiv "Government investment secures $€ 1$ billion for university and private research", UK government press release from HM Treasury, The Rt Hon George Osborne MP and The Rt Hon David Willetts, $8^{\text {th }}$ October 2012. Accessed on $29^{\text {th }}$ October 2015 at https://www.gov.uk/government/news/government-investment-secures-1-billion-for-university-and-private-research--2 ${ }^{x v}$ Dowling, A. (2015) Dowling Review of Business University Research Collaborations, a report for the United Kingdom Department of Business, Innovation and Skills

${ }^{x v i} \mathrm{HM}$ Treasury and Department for Business, Innovation and Skills "Our plan for growth: science and innovation" http://bit.ly/1zrsHrX

xvii The historical developments at the University of Cambridge were informed through an analysis of policy and university document archives, interviews with key stakeholders, and observation from the authors' direct involvement in some of the programmes and partnerships.

xviii Minshall, T., Druilne, C., Probert, D.. (2007). "The evolution of 'third mission' activities at the University of Cambridge: Balancing strategic and operational considerations"
} 


\footnotetext{
xix This committee of the University of Cambridge, supported by the Cambridge City Council, headed by the Head of the Cavendish Laboratory (Sir Nevill Mott) recommended the easing of planning restrictions that had been in place since the 1950 s that had seen companies such as IBM prevented from establishing R\&D facilities in Cambridge.

${ }^{x x}$ University of Cambridge. (1999). Higher Education Reach-Out to Business and the Community Fund: Application for Funding, submission to the Higher Education Funding Council for England

xxi University of Cambridge. (2004). HEIF 2 Application, submission to the Higher Education Funding Council for England

xxii This proposal was not without controversy, as illustrated by http://www.cl.cam.ac.uk/ rja14/expropriation.html

xxiii http://www.cmi.cam.ac.uk/

${ }^{x x i v}$ Robust data on collaborative research and knowledge exchange income from large companies is limited to the period 2005-2014

${ }^{x \times v}$ Perkmann, M., Walsh, W. (2007). "University-industry Relationships and Open Innovation: Towards a Research Agenda" International Journal of Management Reviews 9 (4): 259-80. doi:10.1111/j.1468-2370.2007.00225.x.

xxvi Notes: (i) Collaborative research defined as involving at some degree of public sector sponsorship sector and a material contribution from an external, non-academic organisation to support research performed in collaboration between the university and at least one non-academic collaborator. (ii) Income from large companies covers the following knowledge exchange mechanisms: contract research, consultancy, courses and facilities and equipment services. (iii) Income is measured in constant 2013 prices, having been deflated using a GDP deflator for the UK provided by the UK's HM Treasury. Source: HESA Higher Education Business and Community Interaction Surveys 2005-2014.

xxvii Chesbrough, H. (2003). Open Innovation: The New Imperative for Creating and Profiting from Technology. Boston, Harvard Business School Press.

xxviii Chesbrough, H. 2003. Open Innovation: The New Imperative for Creating and Profiting from Technology. Boston: Harvard Business School Press.

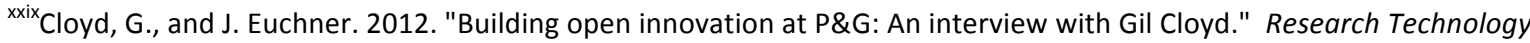
Management 55 (4):14-19

${ }^{x \times x}$ Di Minin, A., F. Frattini, and A. Piccaluga. 2010. "Fiat: OPEN INNOVATION IN A DOWNTURN (1993-2003)." California Management Review 52 (3):132-+.

${ }^{x x x i}$ Sarasvathy, S. D. 2001. "Causation and effectuation: Toward a theoretical shift from economic inevitability to entrepreneurial contingency." Academy of Management Review 26 (2):243-263.

xxxii Mortara, L., and T. Minshall. 2014. "Patterns of implementation of Open Innovation in MNCs " In "New Frontiers in Open Innovation", edited by Henry W. Chesbrough, Wim Vanhaverbeke and Joel West. Oxford: Oxford University Press.

xxxiii Volberda, H. W., F. A. J. Van Den Bosch and O. R. Mihalache (2014). "Advancing management innovation: Synthesizing processes, levels of analysis, and change agents." Organization Studies 35(9): 1245-1264.

xxxiv Lewin, K. . 1946. "Action research and minority problems." J Soc. Issues 2 (4):34-46.

${ }^{x \times x v}$ Chiaroni, D., V. Chiesa, A. De Massis, and F. Frattini. 2008. "The knowledge-bridging role of Technical and Scientific Services in knowledge-intensive industries." International Journal Of Technology Management 41 (3-4):249-272. doi: 10.1504/ijtm.2008.016783.

xxxvi Enkel, E., J. Bell, and H. Hogenkamp. 2011. "Open innovation maturity framework." International Journal of Innovation Management 15 (6):1161-1189.

xxxvii Tushman, M. L. and T. J. Scanlan (1981). "Boundary Spanning Individuals: Their role in information transfer and their antecedents." Academy of Management Journal 24(2): 289-305.
} 